Article

\title{
Uninvited Dinner Guests: A Theoretical Perspective on the Antagonists of Journalism Based on Serres' Parasite
}

\author{
Gerret von Nordheim * and Katharina Kleinen-von Königslöw \\ Department of Journalism and Mass Communication, University of Hamburg, 20146 Hamburg, Germany; \\ E-Mails: gerret.vonnordheim@uni-hamburg.de (G.v.N.), katharina.kleinen@uni-hamburg.de (K.K-v.K.) \\ * Corresponding author
}

Submitted: 30 June 2020 | Accepted: 23 August 2020 | Published: 3 February 2021

\begin{abstract}
In the digital age, the crisis of journalism has been exacerbated by antagonistic actors infiltrating the journalistic system without adhering to its norms or logic. Journalism itself has been ill-prepared to respond to this challenge, but journalism theory and research have also had trouble in grasping these phenomena. It is thus the aim of this article to propose a theoretical perspective on a specific set of antagonists characterized by its paradoxical nature. It is 'the excluded third, included' as described by Serres, the parasite that is both part of the system and its antagonist. From the perspective of systems theory, the parasite is a subsystem that threatens the integrity of the primary system. Thus, the parasite is defined by the relations that describe its position, its behaviour towards the host system. Due to these peculiarities-this contradiction, this vagueness - it evades a classical bivalent logic. This may be one reason why the paradoxical nature of the antagonist from within, the 'uninvited dinner guest,' has not been described as such until now. The parasitic practices follow the logic of the hacker: He is the digital manifestation of Serres' parasite. Accordingly, parasitic strategies can be described as news hacks whose attack vectors target a system's weak points with the help of specific strategies. In doing so, they not only change the system output but also compromise its values and exploit its resources.
\end{abstract}

\section{Keywords}

antagonists; attack vector; hacking; news hacks; parasite; Serres; systems theory

\section{Issue}

This article is part of the issue "Dark Participation in Online Communication: The World of the Wicked Web" edited by Thorsten Quandt (University of Münster, Germany).

(c) 2021 by the authors; licensee Cogitatio (Lisbon, Portugal). This article is licensed under a Creative Commons Attribution 4.0 International License (CC BY).

\section{Introduction}

From a journalistic perspective, the digital age can be described as a phase of differentiation and de-differentiation (Wang, 2020). The clash of old and new media logics in the hybrid media system (Chadwick, 2017) creates a need to engage in boundary work (Carlson \& Lewis, 2019). In our participatory media world, these processes of translation and synchronization do not take place exclusively within the journalistic system. Its blurred, fluid, and permeable boundaries also allow third parties to make an impact without having to subject to system norms. This is the type of actor this article is about-according to Serres, it is "the excluded third, included" (Serres, 2007, p. 76), or also: the parasite.

These actors are distinguished from other antagonistic actors by four particular characteristics: (1) They do not act from outside, they do not try to combat journalists through physical violence or oppression, such as censorship - they act from within; (2) by doing so unilaterally they avail themselves of journalistic resources; (3) they take advantage of the freedoms of a democratic public in pursuit of their strategic goals, compromising the very values on which these freedoms are based; and (4) they are an inherent part of the system (while at the same time being alien to the system) and therefore 
cannot be eliminated without restricting the freedoms (or values) of the system itself.

In recent years, central terms have been coined and frameworks established, which now allow us to analytically describe and classify these actors and their strategies: The term 'information disorder' (Wardle \& Derakhshan, 2017), for example, focuses on various forms of false information and its effects in the hybrid media system (see also Bayer et al., 2019); 'dark participation' (Quandt, 2018) denotes the destructive potential inherent in every participatory technology (see also 'data craft,' Acker, 2018; or 'digital influence machine,' Nadler, Crain, \& Donovan, 2018; or 'alternative influence,' Lewis, 2018); 'source hacking' (Donovan \& Friedberg, 2019) refers to strategies to manipulate digital journalism (see also Phillips, 2018). Despite this great wealth of different concepts, we still lack models to describe these relationships on a theoretical level. To close this gap, we draw on The Parasite, a work by French philosopher Michel Serres (2007). In addition to the biological meaning of the term parasite as an organism living off a host animal (p. 50), Serres (2007) uses an inductive-iterative approach to explore various linguistic levels of meaning of the term 'parasite' - as an uninvited house guest (p. 50) or as disruptive noise (p. 47), called a 'signal parasite' in French. Serres' analyses usually depart from an analogy (for example, a parable, see Section 2.2) and are then projected onto a more general context. Through this abstraction, he is able to overcome the classical bivalent logic, introducing the parasite as an inevitable third party. Serres' trivalent logic has also been incorporated by Luhmann into his systems theory (Luhmann, 2008). Here the parasite is the actor that undermines the functional differentiation of social systems and weakens the boundaries to their environments (Leanza, 2014).

As we study the dynamics of the digital world, the datafication of human behaviour (Couldry \& Yu, 2018), the platformisation of the web ecosystem (Nieborg \& Poell, 2018), and hacking as "digital parasitism" (Aradau, Blanke, \& Greenway, 2019, p. 2548), it becomes clear how relevant and on-point Serres' and Luhmann's theoretical foundations are today. They allow us to classify the above-mentioned sample cases of antagonistic behaviour. For instance, source hacking practices such as "keyword squatting" (Donovan \& Friedberg, 2019, p. 37) or "evidence collages" (Donovan \& Friedberg, 2019 , p. 26) can be described as parasitic news hacks that operate on an attack vector (see Section 4.3), in which they apply strategies, exploit vulnerabilities, manipulate output, compromise values, and appropriate resources.

The model of the news hack thus not only defines the constellation of actors in relation to journalism but also describes the process of a one-way transfer of resources and the gradual undermining of the system's values. It thus associates these parasitic practices with findings on the erosion of trust in the media (Newman, Fletcher, Schulz, Andı, \& Nielsen, 2020, p. 14) or the normaliza- tion of right-wing rhetoric in the mainstream (Larson \& McHendry, 2019, p. 518).

\section{Framework: Theory of Parasites}

\subsection{Paradoxes}

In order to underscore the desideratum of a new terminology for antagonistic actors, we will take up the figure of the "rogue actor" (Entman \& Usher, 2018, pp. 302-303), a notion that suffers from an unresolved theoretical contradiction: According to Entman and Usher (2018), rogue actors violate norms while acting outside of them - they are actors who attack journalism from outside. At the same time, they use the codes of the system, for example, by spreading "entirely baseless false information formatted like traditional news" (Entman \& Usher, 2018, p. 303). Their success is therefore also based on the fact that they do not act exclusively outside the norms, but rather partially harness them whenever it suits their need. We are facing the logical problem of the 'excluded third,' which Serres (2007) describes as follows: "Which is the third part? Or who or what is the third, in this logic of the trenchant decision? Is the third excluded or not? Here we have a trivalent logic where we expected only a bivalent one" (p. 78).

In the concept of 'dark participation,' this trivalence resonates as "negative, selfish or even deeply sinister contributions" (Quandt, 2018, p. 40) to the news-making process. It describes the alien intruder that negates the systemic process, in Serres' words: "The dark side of the system" (Serres, 2007, p. 61). The present study takes up Quandt's concept and adds a relational dimension to it. By describing actors as 'parasitic,' we do not attribute an ontological quality, but rather assign a relational position to antagonistic actors (Leanza, 2014, p. 37) within the journalistic system.

\subsection{Analogies}

The meaning and functioning of a parasitic element is best described via relationships, as Serres shows in his powerful analogies. In his rat parable, he draws on a traditional fairy tale to describe a chain of parasitic constellations (Serres, 2007, pp. 47-65). In keeping with the literal meaning of the Greek word parasite, which refers to an organism that feeds on another (from pará, 'beside,' and sitos, 'food'), the parable is about a city rat who is hosting his visiting cousin, a country rat, at a meal under his landlord's table. The metaphor of the uninvited dinner guests describes the transfer of resources, not only of food but also of social capital-the embarrassment of the ratinfested landlord contrasts with the country rat's admiration of his sophisticated cousin. On the other hand, the parable illustrates the reflexive mechanism (i.e., a mechanism that applies to itself, Luhmann, 1970) of a parasitic relationship: One parasite opens the door to the next by creating access. 
In his systems theory, Niklas Luhmann specifically references the information-theoretical elements of Serres' concept of parasites. Like Serres, albeit in a less abstract way, he uses a parable to illustrate his concept of a parasitic subsystem, which is based on Serres. This is how he describes the commercialization of art:

The opportunity to sell becomes a seduction, quickly attracting parasites who take advantage of this problematic relationship between art and the market, offering advice and mediation services: Please don't make the artwork too large; yes, make it original, because in the language of the market, originality means scarcity, but don't be too eccentric in your execution; perhaps it would be best if you 'redescribed' previous art styles, quote them, parody them, break common boundaries, but make sure the market can still recognize it and relate it to existing art. (Luhmann, 2008, p. 389, authors' translation)

\subsection{Position}

The parasite can be described as a subsystem, an intermediary that mediates between the inside and the outside of the system. Its actions are paradoxical in that it "confirms and rejects the operational closure of its host system" (Leanza, 2014, p. 28). Serres describes it as a "semiconductor" (Serres, 2007, p. 341), its relationships are "one-way streets" (Serres, 2007, p. 106). To this end, the parasite positions itself "in the most profitable positions, at the intersection of relations" (Serres, 2007 , p. 107)-like highwaymen at trade route junctions. Parasites thus also highlight the fault lines of existing orders, their vulnerabilities: "The places where you can shake up a system" (Schmitt, 2011, p. 45, authors' translation).

\subsection{Relation}

The interaction between the embedded parasite and the system can be described by two relations. The first one simply is the parasite's draining of resources without providing any service in return (Serres, 2007, p. 59). This relation of imbalance inevitably leads to the destructionof both the host and the parasite that only exists in relation to it. The second relation is less one-sided-it describes how the presence of the parasite affects the system. According to Serres, a parasite is also the "simplest and most general operator on the variability of systems" (Serres, 2007, p. 324). If we imagine the system as a network, a parasitic node "disidentifies from the network but continues to be appended to it" (Mejias, 2010, p. 615). These nodes introduce noise, interfering with the network "while forcing it to adjust to [their] presence" (Mejias, 2010, p. 615). For Serres, the parasite is, therefore, a disruption "that changes the order, and thus its meaning" (Serres, 2007, p. 313). We call this interdependence the 'compromising relation.'

\subsection{Reflection}

Lastly, the paradox of the parasite is also reflected in the fact that it creates something new. By acting in a different mode of relationality: "The parasite invents something new.... He establishes an unjust pact; relative to the old type of balance, he builds a new one" (Serres, 2007, p. 95). The primary parasite thus enables the next parasite to position itself in a similar relation to the system: "Parasitic orders are parasite-enabling orders" (Leanza, 2014 , p. 37, authors' translation). The reflexive mechanism of the parasite manifests itself as a chain.

In summary, a parasitic element is characterized by four points: (1) The parasite positions itself as an intermediary at system boundaries, more precisely, at existing fault lines. Its interdependence with the system can be described by two relations, which we call (2) a relation of imbalance and (3) a relation of compromise. (4) Its mechanism is reflexive, i.e., it acts as a catalyst for other similar parasitic relations.

\section{Parasites of Journalism: A Relational Approach}

\subsection{The Eufunctional Relation}

Serres' statement about parasites, in general, has always applied to the media system as well: "Real production is undoubtedly rare, for it attracts parasites that immediately make it something common and banal. Real production is unexpected and improbable; it overflows with information and is always immediately parasited" (Serres, 2007, p. 49). The interdependence between media is therefore always fraught with imbalance. In pure newspaper markets, this tendency towards parasitic mimicry used to be compensated for by the value of topicality-information loses its value over time and an information parasite who steals from the printing press would always face a certain time delay. However, the more this time lag was reduced, the more each wave of media innovation was accompanied by clamouring voices accusing the newcomer of parasitically profiting from the original production, with those who were once considered parasites later accusing the next crop of parasites of exploiting their one-sided advantage: Representatives of the printing press successively denounced telegraph companies and their ticker services (Kielbowicz, 2015, p. 27), then the radio (Patnode, 2011, p. 87), and later television (Davies, 1998, p. 25), as parasitic media.

These waves aptly illustrate the phenomenon of differentiation and de-differentiation of systems triggered by parasitic disruption. The evolution of the media ecology's complexities can be described as a re-calibration of system boundaries and a constant re-definition of what is 'inside' and what is 'outside' (see 'boundary work' of Carlson \& Lewis, 2019).

It becomes clear that the system is capable of inclusion up to a certain point-that every differentiation 
is accompanied by a parasitic stage of imbalance that lasts until a new equilibrium is established. This inclusion, however, presupposes that the host and parasite have certain structural similarities. In this context, Schneider distinguishes between parasites "that latch on to the reproductive process of a functional system in either a eufunctional or a dysfunctional way" (Schneider, 2014, p. 100, authors' translation). While eufunctional parasites push into the existing order, dysfunctional parasites don't strive for inclusion, but rather profit from their intermediate status.

\subsection{The Dysfunctional Relation}

The classical dysfunctional parasite, similar to Luhmann's example of the art market, is the actor that commodifies communication-for example through advertising or public relations. Here too, there is a transfer of resources: As McAllister (1996) writes, ads "leech credibility, like a parasite" (p. 140)-he further describes the one-sidedness of the relation as a promotional contamination of the host. The parasitic logic of advertising thus constantly demands new hosts providing ever new, fresh resources. The current stage of this escalation consists of para-journalistic forms that profit from a steady de-differentiation of journalistic system boundaries. Schauster, Ferrucci, and Neill (2016, p. 1416) emphasize that trust in journalism and its credibility suffer particularly from these new forms of advertising (e.g., Native Advertising or Brand Journalism).

The decisive difference between eu- and dysfunctional parasitism is therefore that the latter functions within the system without being fully integrated into it; it follows a logic that is foreign to the system, implanting this logic into the system in the form of noise, thus forcing it to adapt. This not only leads to a loss of resources but also to its values being compromised.

Similarly, we can locate other forms of persuasive communication in a dysfunctional relationship to these values and their vehicles. For instance, the oftenobserved paradoxical relationship between populism and journalism-Haller and Holt speak of "paradoxical populism" (Haller \& Holt, 2018, p. 1665)-also fits the inherently paradoxical notion of the parasite. In fact, populism has repeatedly been described as a parasite of democratic values (Fournier, 2019; Urbinati, 2014). Fournier (2019) also points out its paradoxical nature when he writes that populism is "inherent to the features of constitutional democracy" (p. 381) while at the same time pursuing the "objective to destroy the same constitutional system" (p. 364). Urbinati (2014) stresses that once populism attains its goal of dominating a democratic state, "it can modify its figure radically" (p. 135). This mechanism of destructive modification from within is what we mean by the 'compromising relation.' Bayer et al. (2019) describe this process with the help of the populist method of strategic disinformation:
False information in itself (if it does not violate others' reputation, for example) enjoys the protection of freedom of expression, but when the whole environment of public discourse becomes occupied and dominated by falsehood, it frustrates the primary purpose of freedom of expression. (Bayer et al., 2019, p. 79)

The parasite thus uses the freedoms of the system to compromise the values from which these very freedoms are derived. The strategy of compromising becomes particularly clear in the example of the "lying demagogue" (Hahl, Kim, \& Zuckerman Sivan, 2018, p. 1), who violates various norms (in particular, truthfulness) so obviously that the establishment is compelled to distance itself from this actor: "But this very need by the establishment to distance itself from the lying demagogue lends credibility to his claim to be an authentic champion for those who feel disenfranchised by that establishment" (Hahl et al., 2018, p. 8). As a consequence, anyone who abides by the norms, who is not ostracized by the establishment as a pariah, appears "less obviously committed to challenging it" (Hahl et al., 2018, p. 8). This also, and primarily, concerns the authority of journalistic actors who act as watchdogs within the norms of a competitive democracy (Strömbäck, 2005, p. 332).

This pattern can be applied to various strategies employed by antagonistic actors. For example, the strategy of "leak forgery" (i.e., a politically instrumentalized data breach; see Donovan \& Friedberg, 2019, p. 18) is parasitic to the value of anonymity and the journalistic freedom of source protection. The strategy of "pseudoscience" (Hartzell, 2018, p. 17), i.e., camouflaging strategic information as a study, etc., is parasitic to the deliberative value of rationality. The value of representation is compromised by dark participation, by "sock puppets" or "deep cover" strategies (Acker, 2018, p. 14). The freedom of identity and self-development is undermined by 'hate spins' (George, 2016), the value of political agonism (Mouffe, 2000) is undermined by "strategic controversy" (Lewis, 2018, p. 31), etc.

It remains unclear, however, what changes to the journalistic system enabled these parasitic chains. As was the case with earlier disruptions, the decisive impulse for differentiation is technological innovation. In contrast to earlier differentiation waves, however, this one has spawned an actor who opens the system boundaries to the outside, positioning itself as an intermediary on the system boundaries: the platform.

\section{Parasites of the Digital Realm}

The relationship between journalism and the major information intermediaries (Helberger, Kleinen-von Königslöw, \& van der Noll, 2015)-i.e., the platforms Google, YouTube, Facebook, Instagram, Twitter, etc.can be described as a process of differentiation and mutual dependence, attraction, and repulsion, aptly culminating in the paradoxical term 'frenemies' (Bell, 2015), 
which means the same thing as Serres' notion of the 'included third.' In fact, in a relatively short period of time, platform companies managed to create a situation where the direction of the parasitic relation is not always evident. The example of the platforms makes it all too clear that this relation is a matter of perspective: In the polygon between user, platform, content provider, advertiser, etc., anyone can be host or parasite. In fact, the platform completely dissolves the bivalent distinction between parasite and host.

In the digital sphere, "life-processes must be converted into streams of data inputs for computer-based processing" (Couldry \& Yu, 2018, p. 4473). The parasitic medium - a by-product of the actual interactionmaterializes in this process of datafication. Nowhere is this more obvious than in the digital world, where any instance of communication opens a door to parasitic third-party use-datafication is a "legitimate means to access...people's behavior" (Van Dijck, 2014, p. 198, emphasis in the original). In a second logical step, the parasite itself acts as host, enabling and catalysing the very type of interaction whose secondary product it desiresto use another one of Serres' analogies (2007, p. 160): The "farmer parasites the fauna." In the digital world, this evolution of a parasitic logic is described as platformisation: "The penetration of economic, governmental, and infrastructural extensions of digital platforms into the web and app ecosystems, fundamentally affecting the operations of the cultural industries" (Nieborg \& Poell, 2018, p. 4276, emphasis in the original). The parasite becomes an infrastructure in its own right, striving for a monopoly and exponentially increasing its influence.

Assuming the perspective of journalism, we quickly grasp the extent of the parasitic behaviour of the actor 'platform' towards the system. The relation of imbalance is most clearly reflected in the "parasitic relationship to news production" (Siapera, 2013, p. 17), along with a radical redistribution of advertising revenues in favour of digital platforms (Bell \& Owen, 2017). They combine and scale up the above-described logics of advertising communication and competing media. At the same time, they leverage their position as a parasitic host to disruptively de- and recode system norms. For the Facebook algorithm, Caplan and Boyd (2018) describe this compromising effect as an isomorphism. They observed: "How algorithms structure disparate businesses and aims into an organizational field, leading them to change their goals and adopt new practices" (Caplan \& Boyd, 2018, p. 2). In the tradition of isomorphism and bureaucracy research, algorithms are therefore to be considered an "extension of bureaucratic tools such as forms" (Caplan \& Boyd, 2018, p. 3). Similarly, Serres describes the bureaucratic power "to edit the laws and to withdraw knowledge from the greatest number" (Serres, 2007, p. 98). This particular "theft of information" (Serres, 2007, p. 97) is also characteristic of the platforms' algorithms - they act as unproclaimed laws without having to be transparent. For journalism, this means that "by defining and re- defining the concept of relevance or 'value' of information and news media, Facebook increasingly writes the rules, or code, that defines which content succeeds or fails" (Caplan \& Boyd, 2018, p. 5).

\subsection{Parasitic Infrastructure}

But platforms are not the only parasites feeding on journalism. Due to the reflexive nature of parasitism described above, they also function as "opportunity structures" (Ernst, Esser, Blassnig, \& Engesser, 2019, p. 170) for other actors to act co-parasitically alongside. They form a powerful sub-system that opens the boundaries of the journalistic system to various forms of attackers who use the platform logic as a parasitic infrastructure.

Bayer et al. (2019) note that "the interests of the technology providers (online platforms, social networks, and digital advertisers) and the actors behind [the] disinformation campaign[s] are to some extent aligned" ( $p$. $31)$. Both seek the users' attention, yet rather than competing for this resource, they support each other symbiotically: The actors behind disinformation campaigns have a "full suite of services" (Bayer et al., 2019, p. 32) at their disposal, made available to them by the platforms. Central tools for this are monitoring, profiling, targeting, and automatic optimization of target publics, as well as having the timing, placement, and content of influence campaigns based on consumer data and real-time feedback (Nadler et al., 2018, p. 11). Many of these strategic communication techniques are not newbut the parasitic infrastructure "accelerates their reach, hones their precision, and offers the means to evade detection and penalties" (Nadler et al., 2018, p. 27). This behaviour contrasts starkly with the platforms' projected self-image as champions of democratic values such as neutrality and equality (Gillespie, 2010, p. 352). They "largely deny responsibility for quality and accuracy of the frames they disseminate and profit from, thereby giving rogue actors and ideological media power to distort democracy" (Entman \& Usher, 2018, p. 306).

\subsection{Border Crossers}

The current omnipresence of political-strategic actors who position themselves mid-way between journalistic mainstream discourse and extremist ideologies can only be understood in the context of this co-parasitic synergy. Here too, parasitic relations are at play, following the paradoxical logic of the included third. From their intermediary position, they are able to draw attention away from the democratic discourse (relation of imbalance), to mobilize and recruit; while at the same time invoking the values of democratic discourse to claim a role as a legitimate spokesperson, thus successively undermining it (compromising relation).

They benefit from their "lack of ideological cohesion, leadership and organization" (Fielitz \& Marcks, 
2019, p. 7)-a blurry strategy in whose haze they can cross back and forth between the mainstream discourse, dominated by journalism, and the undemocratic outside. Accordingly, the 'alt-right' functions "as a rhetorical bridge between white nationalism and the mainstream public" (Hartzell, 2018, p. 24). As Hartzell (2018) explains, this intermediary position allows right-wing actors to either act in proximity to extremist ideology or to temporarily distance themselves from it (e.g., after a terrorist attack or right-wing riots), whatever is most opportune in a given situation (p. 24).

A parasite defines itself through its relation, which also means that it cannot exist without a reference point or host. Here, this need to act in relation to a host is reflected in the euphemistic claim to represent an alternative (see also Holt, Ustad Figenschou, \& Frischlich, 2019; for alternative media; Lees, 2018; for 'Alternative for Germany,' etc.). As Mészáros (2005) aptly puts it, the strategy of these "alternative" groups consists in "dismissing their adversary with an aprioristic negativity, remaining thus entirely dependent (i.e., intellectually parasitic) on the arguments" (p. 257, emphasis in the original) of the other side.

The 'alternative' aspect is thus primarily a pose intended to legitimize the demand for visibility in the democratic discourse. Right-wing actors consequently present themselves as marginalized and discriminated against by the mainstream. On social media, they share stories about their 'coming out' as conservatives, demanding "ideological diversity" in the mainstream (Lewis, 2018, pp. 21-22). As Lewis (2018) points out, this countercultural positioning is misleading: "These influencers are adopting identity signals affiliated with previous countercultures, but the actual content of their arguments seeks to reinforce dominant cultural racial and gendered hierarchies" (p. 24).

It is therefore important to distinguish this mimicry from the phenomenon of counterpublics (Fraser, 1990), which can be classified as eufunctional parasites: Although they do not always strive for symbiosis with the dominant public, they share the basic values of the dominant system. In contrast, Larson and McHendry (2019) describe the alleged 'alternative' publics as "parasitic publics...that feed off of oppressive conditions in the public sphere by articulating with dominant discourses to exploit dominant publics' centripetal force" (p. 519). Here, too, the compromising relation becomes evident: The value of diversity, the inclusive centripetal force of the democratic public sphere, is abused in order to weaken it and thus cause a "societal norm shift" (Quandt, 2018, p. 43).

\subsection{Parasitic Strategies}

Contrary to the public image projected by its representatives (as 'alternative' or 'countercultural'), a parasitic element is not capable of creating something original on its own-its innovative power consists solely in putting existing things into new relations, channelling away resources, and compromising values. In a networklike information environment, the parasitic element is the node that generates noise, thus stirring up 'information disorder' (Wardle \& Derakhshan, 2017): It disidentifies from the network by means of disinformation (false information shared to cause harm) or malinformation (genuine information shared to cause harm), thus forcing other nodes to adapt (or at least irritating them). One result, for instance, is the spread of misinformation (spreading false information without malicious intent; for the distinction between dis-, mal-, and misinformation, see Wardle \& Derakhshan, 2017, p. 5).

The parasitic strategies stem from a variety of origins: Propaganda techniques (Lukito et al., 2020) work synergistically with (online) marketing tools (Donovan \& Friedberg, 2019) and the insider knowledge of former journalists who now publish in partisan or alternative media (Phillips, 2018, p. 12). In parasitic chains, the function of such 'alternative' journalists is to "launder" (Donovan \& Friedberg, 2019, pp. 16, 24), i.e., lend legitimacy to slogans and narratives from social media for populist actors to pick up and carry into the political discourse.

Moreover, many parasitic techniques can be traced back to the digital subculture of hacking or its subforms "social hacking" (Kerr \& Lee, 2019, p. 11) or trolling (Phillips, 2018, p. 19). Like "a parasite, hacking draws all its strength, strategies and tools from the system on which and in which it operates" (Gunkel, 2001, p. 6). At the same time, hacking does not introduce anything new into the system: "It derives everything from the host's own protocols and procedures" (Gunkel, 2001, p. 6). According to Aradau et al. (2019), hacks are thus '“acts of digital parasitism,' which create parasitic interferences by working beside or alongside digital technologies and assembling collectives of coders and non-coders" (p. 2548). In this sense, hacking can be understood as an overarching umbrella term for a wide variety of parasitic practices in the digital world.

The news hackers' strategies-called 'exploits' in IT security lingo-target the weak spots of the journalistic system or, to use the term from earlier, its predetermined fault lines. It is often difficult to identify whether such vulnerabilities are due to a lack of journalistic diligence, a lack of competence, or digital naivety ("anything x.0"; see Quandt, 2018, p. 38), or research practices that are prone to manipulation (Lukito et al., 2020; McGregor, 2019)-or whether it is simply a lack of financial resources to defend against attack. News hacks aim to manipulate editorial output, i.e., distort the tone, volume, and journalistic agenda (cf. media bias of Eberl, Boomgaarden, \& Wagner, 2017). However, as we have seen, the attack vector does not end here-it also compromises values and exploits resources (Figure 1).

Thus, certain news hacks such as "keyword squatting" (co-opting of keywords or accounts related to breaking news events, social movements, etc., to manipulate 


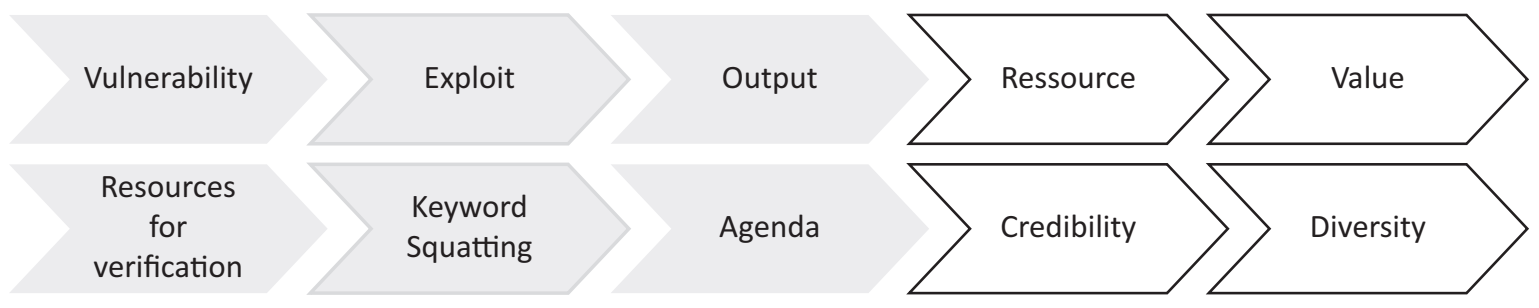

Figure 1. Parasitic attack vector. Note: The starting point is identifying a predetermined fault line or vulnerability (e.g., lack of resources, lack of competence etc.), in the case described here a lack of resources for verification of user-generated content; then an exploit is applied (keyword squatting, leak forgery, strategic controversy etc.), manipulating an output (volume, agenda or tonality of reporting) leading to resources being appropriated by the parasitic relations (e.g., information, reputation, credibility, trust, authority, attention) and values being compromised (e.g., truthfulness, rationality, representation, identity, agonism).

search traffic; Donovan \& Friedberg, 2019, p. 37) or "evidence collages" (compiling a blend of verified and unverified information; Donovan \& Friedberg, 2019, p. 26) not only prey on weaknesses in journalistic practices (e.g., lack of resources/competencies for verification, homophilia, metrics orientation, partisan bias, false balance) and distortions of journalistic content (e.g., manipulated saliences in the agenda). The relational-parasitic angle highlights that beyond this, news hacks unfold their real impact by also diminishing journalistic resources (credibility, authority, attention, etc.) and damaging values (participation, diversity, truthfulness, etc.).

\section{Conclusions}

The antagonist of the journalistic system described in this article is characterized by its paradoxical nature. It is the 'the excluded third, included' as described by Serres, the parasite that is both part of the system and its antagonist. From the perspective of systems theory, the parasite is a subsystem that threatens the integrity of the primary system.

The notion of the parasite is not new to the media system-as we have retraced in this article, the differentiation and integration of new media or logics that are alien to the system (e.g., advertising) and the resulting tensions can be described as parasitic relations. While these tensions between the host and structurally similar, eufunctional parasites can be resolved by way of de-differentiation or inclusion, the presence of dysfunctional parasites will successively weaken the system. These parasites do not strive for inclusion but benefit from their intermediate position, from which they drain resources (relation of imbalance) and introduce noise into the system to force a de-coding of system values (compromising relation).

Thus, the parasite is not defined by characteristics in the ontological sense, but mainly by certain relations that describe its position, its behaviour towards the host system. Due to these peculiarities-this contradiction, this vagueness - it evades a classical bivalent logic (Serres, 2007, p. 275). This may be one reason why the paradoxical nature of the antagonist from within, the 'uninvited dinner guest,' has not been described as such until now. The present work seeks to help close this gap by adding a relational perspective to concepts such as 'rogue actors' (Entman \& Usher, 2018) or 'dark participation' (Quandt, 2018).

Intermediary platforms were identified as a central parasitic infrastructure in relation to which strategic communicators behave co-parasitically in the sense of a reflexive mechanism. Their practices follow the parasitic logic of the hack, which draws all its "strength, strategies and tools from the system" (Gunkel, 2001, p. 6). The hacker is the digital manifestation of Serres' parasite. Accordingly, parasitic strategies can be described as news hacks whose attack vectors target a system's weak points with the help of specific exploits. In doing so, they not only change the system output, but also compromise its constitutive values and exploit its vital resources.

This systematization of parasitic relations can serve as a starting point for future analyses of antagonistic actors and their practices. In this article, we were only able to merely allude that from the perspective of the journalistic system, various forms of strategic communication can be described as dysfunctional parasites, for example populist rhetoric, demagogy, but also practices of the alt-right. Follow-up case studies could be conducted to further deepen these analyses. For a comprehensive view, research projects could use the attack vector model, starting by questioning how journalists behave in the digital space and which journalistic practices make them vulnerable to attack (analytical focus: journalistic practice, as seen, for example, in McGregor, 2019; McGregor \& Molyneux, 2020). The second step would be to identify and describe the strategies news hackers use to exploit these previously identified vulnerabilities, with a special focus on the technical infrastructure that makes the attack possible in the first place (analytical focus: parasitic practice and infrastructure, as seen, for example, in Donovan \& Friedberg, 2019; Phillips, 2018). At the output level, the question is how content is manipulated, how parasitic strategies change reporting (analytical focus: content, as seen, for example, 
in Lukito et al., 2020). These three levels and their associated mechanisms are put into an analytical context by their parasitic relations. For example, the relation of imbalance could be operationalized as a loss of news credibility, caused, for instance, by a lack of civility in user comments (for example in Prochazka, Weber, \& Schweiger, 2018). At the same time, following the notion of a one-sided exchange, the question would be which actors benefit from this loss of resources; whether, for example, the loss of credibility on the journalistic side goes hand in hand with an increased willingness to believe in alternative media (see 'displacement effect,' for example, in Omar \& Ahrari, 2020).

Lastly, the relation of compromise allows us to evaluate parasitic practices in the context of democratic values. News hacks are always based on liberal system norms, degrees of freedom that can be leveraged with various intentions-and not always in accordance with their original rationale. Parasites exploit this ambivalence, thus compromising the value of the norm. Measures taken against these harmful practices are therefore often directed against the freedoms and values themselves. This restrictive backlash can be observed at various levels: Newsrooms shut down their comment sections (Quandt, 2018, p. 37), platforms delete harmless content in response to manipulation attempts (Acker, 2018 , p. 4), journalists' rights are restricted in favour of secret services' scope of authority (cf. the discussion on the German 'state Trojan' and digital source protection in Meister, 2020). Measures like these are a contradiction of the very system, which in turn can lead to loss of credibility and legitimacy. Referring to Popper, Fielitz and Marcks (2019) claim that this dilemma is an inevitable consequence, a "reloaded 'paradox of tolerance,"' "being intolerant of (liberal) structures producing intolerance" (p. 3). Destructive measures, however, can only be legitimate as a last resort and must be critically questioned if presented as the only alternative. Preference should be given to constructive measures that identify vulnerabilities and apply 'patches' to eliminate them (for example in journalistic training or in terms of resources).

One limitation of these perspectives is the fact that they are retrospective, meaning that they are only partially suited for prevention. If research does not want to be reduced to taking stock of damage done and reconstructing events that have already happened, it must find ways to anticipate future developments. As a possible solution to this communication science dilemma, Schäfer and Wessler (2020) suggest considering sociotechnical innovations "that are (potentially) relevant to public communication" (p. 308), and to thus identify potential risks at an early stage as "interventionist innovation research" (p. 309). In addition, it could be useful to look into IT security strategies (simulated attacks, honeypot scenarios, sensitization) or organizational and design principles for risk management, such as diversification, to see whether they could be adapted for preventive research.

\section{Acknowledgments}

The authors would like to thank the four anonymous reviewers as well as the Academic Editors for their valuable and constructive feedback on the manuscript.

\section{Conflict of Interests}

The authors declare no conflict of interests.

\section{References}

Acker, A. (2018). Data craft: The manipulation of social media metadata. New York, NY: Data \& Society's Media Manipulation Research Initiative. Retrieved from https://datasociety.net/wp-content/uploads/ 2018/11/DS_Data_Craft_Manipulation_of_Social_ Media_Metadata.pdf

Aradau, C., Blanke, T., \& Greenway, G. (2019). Acts of digital parasitism: Hacking, humanitarian apps and platformisation. New Media \& Society, 21(11/12), 2548-2565. https://doi.org/10.1177/ 1461444819852589

Bayer, J., Bitiukova, N., Bard, P., Szakács, J., Alemanno, A., \& Uszkiewicz, E. (2019). Disinformation and propaganda: Impact on the functioning of the rule of law in the EU and its member states. Brussels: European Parliament's Committee on Civil Liberties, Justice and Home Affairs (LIBE). Retrieved from https:// www.europarl.europa.eu/RegData/etudes/STUD/ 2019/608864/IPOL_STU(2019)608864_EN.pdf

Bell, E. (2015, April 30). Google and Facebook are our frenemy. Beware. Columbia Journalism Review. https://www.cjr.org/analysis/google_facebook_ frenemy.php

Bell, E. J., \& Owen, T. (2017). The platform press: How Silicon Valley reengineered journalism. New York, NY: Tow Center for Digital Journalism.

Caplan, R., \& Boyd, D. (2018). Isomorphism through algorithms: Institutional dependencies in the case of Facebook. Big Data \& Society, 5(1), 1-12. https:// doi.org/10.1177/2053951718757253

Carlson, M., \& Lewis, S. C. (2019). Boundary work. In K. Wahl-Jorgensen \& T. Hanitzsch (Eds.), The handbook of journalism studies (2nd ed., pp. 123-135). London: Routledge.

Chadwick, A. (2017). The hybrid media system. Oxford: Oxford University Press.

Couldry, N., \& Yu, J. (2018). Deconstructing datafication's brave new world. New Media \& Society, 20(12), 4473-4491. https://doi.org/10.1177/ 1461444818775968

Davies, D. R. (1998). From ridicule to respect: Newspapers' reaction to television, 1948-1960. American Journalism, 15(4), 17-33. https://doi.org/10.1080/ 08821127.1998.10739140

Donovan, J., \& Friedberg, B. (2019). Source hacking: Media manipulation in practice. New York, NY: Data 
\& Society's Media Manipulation Research Initiative. Retrieved from https://datasociety.net/wp-content/ uploads/2019/09/Source-Hacking_Hi-res.pdf

Eberl, J.-M., Boomgaarden, H. G., \& Wagner, M. (2017). one bias fits all? Three types of media bias and their effects on party preferences. Communication Research, 44(8), 1125-1148. https://doi.org/ $10.1177 / 0093650215614364$

Entman, R. M., \& Usher, N. (2018). Framing in a fractured democracy: Impacts of digital technology on ideology, power and cascading network activation. Journal of Communication, 68(2), 298-308. https:// doi.org/10.1093/joc/jqx019

Ernst, N., Esser, F., Blassnig, S., \& Engesser, S. (2019). Favorable opportunity structures for populist communication: Comparing different types of politicians and issues in social media, television and the press. The International Journal of Press/Politics, 24(2), 165-188. https://doi.org/10.1177/1940161218819 430

Fielitz, M., \& Marcks, H. (2019). Digital fascism: Challenges for the open society in times of social media. Berkeley, CA: Berkeley Center for Right-Wing Studies. Retrieved from https://escholarship.org/uc/ item/87w5c5gp

Fournier, T. (2019). From rhetoric to action, a constitutional analysis of populism. German Law Journal, 20(3), 362-381. https://doi.org/10.1017/glj.2019.22

Fraser, N. (1990). Rethinking the public sphere: A contribution to the critique of actually existing democracy. Social Text, 25. https://doi.org/10.2307/466240

George, C. (2016). Hate spin: The manufacture of religious offense and its threat to democracy. Cambridge, MA: The MIT Press.

Gillespie, T. (2010). The politics of 'platforms.' New Media \& Society, 12(3), 347-364. https://doi.org/ $10.1177 / 1461444809342738$

Gunkel, D. J. (2001). Hacking cyberspace. Boulder, CO: Westview Press.

Hahl, O., Kim, M., \& Zuckerman Sivan, E. W. (2018). The authentic appeal of the lying demagogue: Proclaiming the deeper truth about political illegitimacy. American Sociological Review, 83(1), 1-33. https:// doi.org/10.1177/0003122417749632

Haller, A., \& Holt, K. (2018). Paradoxical populism: How PEGIDA relates to mainstream and alternative media. Information, Communication \& Society. https://doi. org/10.1080/1369118X.2018.1449882

Hartzell, S. L. (2018). Alt-white: Conceptualizing the "altright" as a rhetorical bridge between white nationalism and mainstream public discourse. Journal of Contemporary Rhetoric, 8(1/2), 6-25.

Helberger, N., Kleinen-von Königslöw, K., \& van der Noll, R. (2015). Regulating the new information intermediaries as gatekeepers of information diversity. Info, 17(6), 50-71. https://doi.org/10.1108/info-05-20150034

Holt, K., Ustad Figenschou, T., \& Frischlich, L. (2019).
Key dimensions of alternative news media. Digital Journalism, 7(7), 860-869. https://doi.org/10.1080/ 21670811.2019.1625715

Kerr, E., \& Lee, C. A. L. (2019). Trolls maintained: Baiting technological infrastructures of informational justice. Information, Communication \& Society, 1-18. https://doi.org/10.1080/1369118X.2019.1623903

Kielbowicz, R. B. (2015). Regulating timeliness: Technologies, laws, and the news, 1840-1970. Journalism \& Communication Monographs, 17(1), 5-83. https:// doi.org/10.1177/1077699014566380

Larson, K. R., \& McHendry, G. F. (2019). Parasitic publics. Rhetoric Society Quarterly, 49(5), 517-541. https:// doi.org/10.1080/02773945.2019.1671986

Leanza, M. (2014). Grenzrauschen: Zur Figur des Parasiten in der Systemtheorie [Border noise: On the figure of the parasite in systems theory]. BEHEMOTH: $A$ Journal on Civilisation, Das Andere der Ordnung, 28. https://doi.org/10.6094/BEHEMOTH.2014.7.1.771

Lees, C. (2018). The 'Alternative for Germany': The rise of right-wing populism at the heart of Europe. Politics, 38(3), 295-310. https://doi.org/10.1177/ 0263395718777718

Lewis, R. (2018). Alternative influence: Broadcasting the reactionary right on YouTube. New York, NY: Data \& Society's Media Manipulation Research Initiative. https://datasociety.net/wp-content/uploads/2018/ 09/DS_Alternative_Influence.pdf

Luhmann, N. (1970). Reflexive Mechanismen [Reflexive mechanisms]. In N. Luhmann (Ed.), Soziologische Aufklärung 1: Aufsätze zur Theorie sozialer Systeme [Sociological education 1: Essays on the theory of social systems] (pp. 92-112). Wiesbaden: VS Verlag für Sozialwissenschaften. https://doi.org/ 10.1007/978-3-322-96984-2_5

Luhmann, N. (2008). Schriften zu Kunst und Literatur [Texts on art and literature]. Berlin: Suhrkamp.

Lukito, J., Suk, J., Zhang, Y., Doroshenko, L., Kim, S. J., Su, M.-H., Xia, Y., Freelon, D., \& Wells, C. (2020). The wolves in sheep's clothing: How Russia's Internet research agency tweets appeared in U.S. news as vox populi. The International Journal of Press/Politics, 25(2), 196-216. https://doi.org/ 10.1177/1940161219895215

McAllister, M. P. (1996). The commercialization of American culture: New advertising, control, and democracy. London: Sage.

McGregor, S. C. (2019). Social media as public opinion: How journalists use social media to represent public opinion. Journalism, 20(8), 1070-1086. https:// doi.org/10.1177/1464884919845458

McGregor, S. C., \& Molyneux, L. (2020). Twitter's influence on news judgment: An experiment among journalists. Journalism, 21(5), 597-613. https://doi.org/ $10.1177 / 1464884918802975$

Meister, A. (2020, June 18). Staatstrojaner für Geheimdienste: "Tritt die Regelung in Kraft, werden wir dagegen klagen" [State Trojan for intelligence ser- 
vices: "If the regulation is enacted, we will appeal it"]. Netzpolitik. Retrieved from https://netzpolitik.org/ 2020/staatstrojaner-fuer-geheimdienste-tritt-dieregelung-in-kraft-werden-wir-dagegen-klagen

Mejias, U. A. (2010). The limits of networks as models for organizing the social. New Media \& Society, 12(4), 603-617. https://doi.org/10.1177/14614448 09341392

Mészáros, I. (2005). The power of ideology. London: Zed Books.

Mouffe, C. (2000). The democratic paradox. London: Verso.

Nadler, A., Crain, M., \& Donovan, J. (2018). Weaponizing the digital influence machine: The political perils of online ad tech. New York, NY: Data \& Society's Media Manipulation research initiative. Retrieved from https://datasociety.net/library/ weaponizing-the-digital-influence-machine

Newman, N., Fletcher, R., Schulz, A., Andı, S., \& Nielsen, R. K. (2020). Reuters Institute digital news report 2020. Oxford: Reuters Institute for the Study of Journalism.

Nieborg, D. B., \& Poell, T. (2018). The platformization of cultural production: Theorizing the contingent cultural commodity. New Media \& Society, 20(11), 4275-4292. https://doi.org/10.1177/ 1461444818769694

Omar, B., \& Ahrari, S. (2020). Mainstream and nonmainstream media in Malaysia: Does lack of credibility lead to displacement? Newspaper Research Journal, 41(2), 127-145. https://doi.org/10.1177/ 0739532920919825

Patnode, R. (2011). Friend, foe, or freeloader? Cooperation and competition between newspapers and radio in the early 1920s. American Journalism, 28(1), 75-95. https://doi.org/10.1080/ 08821127.2011 .10678182

Phillips, W. (2018). The oxygen of amplification: Better practices for reporting on extremists, antagonists, and manipulators. New York, NY: Data \& Society's Media Manipulation Research Initiative. Retrieved from https://datasociety.net/wp-content/ uploads/2018/05/1_PART_1_Oxygen_of_ Amplification_DS.pdf

Prochazka, F., Weber, P., \& Schweiger, W. (2018). Effects of civility and reasoning in user comments on perceived journalistic quality. Journalism Studies, 19(1), 62-78. https://doi.org/10.1080/ 1461670X.2016.1161497

Quandt, T. (2018). Dark participation. Media and Communication, 6(4), 36-48. https://doi.org/10.17645/ mac.v6i4.1519

Schäfer, M. S., \& Wessler, H. (2020). Öffentliche Kom- munikation in Zeiten künstlicher Intelligenz: Warum und wie die Kommunikationswissenschaft Licht in die Black Box soziotechnischer Innovationen bringen sollte [Public communication in times of artificial intelligence: Why and how communication science should crack open the black box of sociotechnical innovations]. Publizistik, 65(3), 307-331. https://doi. org/10.1007/s11616-020-00592-6

Schauster, E. E., Ferrucci, P., \& Neill, M. S. (2016). Native advertising is the new journalism: How deception affects social responsibility. American Behavioral Scientist, 60(12), 1408-1424. https://doi.org/10.1177/ 0002764216660135

Schmitt, M. (2011). Parasitäre Strukturbildung: Einsichten aus System-und Netzwerktheorie in die Figur des Parasiten [Parasitic structure formation: Insights from system and network theory into the figure of the parasite]. In B. P. Priddat \& M. Schmid (Eds.), Korruption als Ordnung zweiter Art [Corruption as an order of the second kind] (pp. 43-59). Wiesbaden: VS Verlag für Sozialwissenschaften. https://doi.org/10.1007/978-3-531-93011-4_3

Schneider, W. L. (2014). Parasiten sozialer Systeme [Parasites of social systems]. In B. Heintz \& H. Tyrell (Eds.), Interaktion-Organisation-Gesellschaft revisited [Interaction-Organization-Society revisited] (pp. 86-108). Berlin: De Gruyter.

Serres, M. (2007). The parasite. Minneapolis, MN: University of Minnesota Press.

Siapera, E. (2013). Platform infomediation and journalism. Culture Machine, 14, 1-28.

Strömbäck, J. (2005). In search of a standard: Four models of democracy and their normative implications for journalism. Journalism Studies, 6(3), 331-345. https://doi.org/10.1080/14616700500131950

Urbinati, N. (2014). Democracy disfigured: Opinion, truth, and the people. Cambridge, MA: Harvard University Press.

Van Dijck, J. (2014). Datafication, dataism and dataveillance: Big data between scientific paradigm and ideology. Surveillance \& Society, 12(2), 197-208. https://doi.org/10.24908/ss.v12i2.4776

Wang, Q. (2020). Differentiation and de-differentiation: The evolving power dynamics between news industry and tech industry. Journalism \& Mass Communication Quarterly, 97(2), 509-527. https://doi.org/ 10.1177/1077699020916809

Wardle, C., \& Derakhshan, H. (2017). Information disorder: Toward an interdisciplinary framework for research and policy making (Report No. 27). Strasbourg: Council of Europe. 


\section{About the Authors}

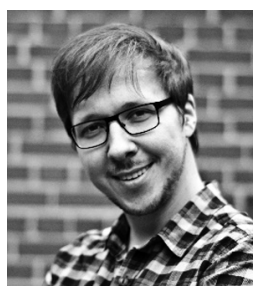

Gerret von Nordheim is a Postdoctoral Researcher in the field of communication science at the University of Hamburg. His research focuses on intermedia effects in the hybrid media system, especially between journalism, social media, and populist actors. He is specialized in the field of computational methods.

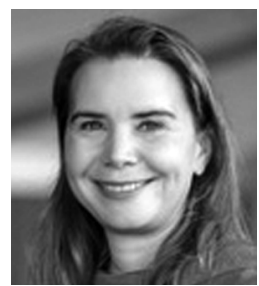

Katharina Kleinen-von Königslöw is a Professor for Journalism and Communication Studies, with a focus on Digital Communication and Sustainability at the Universität Hamburg. Her research focuses on the impact of digitalisation and technological innovations on political communication and, in particular, the role of social network platforms and their use by citizens and political actors. 